\title{
CARNOSINE IN PRIMARY AFFERENTS OF THE OLFACTORY SYSTEM: AN AUTORADIOGRAPHIC AND BIOCHEMICAL STUDY ${ }^{1}$
}

\author{
GAIL D. BURD,, ${ }^{* 2}$ BARRY J. DAVIS, ${ }^{*}$ FOTEOS MACRIDES, ${ }^{*, 3}$ MARY GRILLO, $\ddagger$ AND \\ FRANK L. MARGOLIS $\ddagger$ \\ ${ }^{*}$ Worcester Foundation for Experimental Biology, Shrewsbury, Massachusetts 01545 and ${ }^{\ddagger}$ Roche Institute of Molecular \\ Biology, Nutley, New Jersey 07110
}

Received August 3, 1981; Revised October 14, 1981; Accepted October 16, 1981

\begin{abstract}
Previous in vivo studies have shown that $\beta$-alanine is incorporated specifically into the dipeptide L-carnosine ( $\beta$-alanyl-L-histidine). In the present study, we administered $\beta-\left[{ }^{3} \mathrm{H}\right]$ alanine to the nasal cavity of hamsters and used biochemical analyses to identify the radioactively labeled compounds in the olfactory epithelium and olfactory bulb and autoradiography to demonstrate the localization and transport of the label in the primary afferents of the olfactory system. The olfactory epithelium and lamina propria were labeled intensely $6 \mathrm{hr}$ after intranasal $\beta-\left[{ }^{3} \mathrm{H}\right]$ alanine administration. At this survival time, $61 \%$ of the radioactivity in the olfactory epithelium was present in the carnosine fraction, while $37 \%$ of the label remained in the $\beta$-alanine fraction. After 24 -hr and 4-day survival periods, greater than $82 \%$ of the radioactivity was present in the carnosine fraction, and the olfactory receptors and bundles of axons were labeled preferentially. The olfactory nerve and glomerular layers of the main olfactory bulb were labeled intensely at 6 and $24 \mathrm{hr}$ after $\beta-\left[{ }^{3} \mathrm{H}\right]$ alanine administration; much less label was present in these layers at 4 days survival. At all three of these survival times, greater than $84 \%$ of the radioactivity in the olfactory bulb was present in the carnosine fraction. No label was present in the olfactory epithelium or bulb 18 days after $\beta$ $\left[{ }^{3} \mathrm{H}\right]$ alanine administration. While the autoradiographic labeling over the structures of the accessory olfactory system was consistently less intense than that over the main olfactory system structures, the patterns of labeling were similar over the four survival times. Intranasal $\alpha-\left[{ }^{3} \mathrm{H}\right]$ alanine administration resulted in some labeling in the primary afferent fibers, but the labeling did not have the specificity nor the same time course over the four survival times that was observed after $\beta$ $\left[{ }^{3} \mathrm{H}\right]$ alanine administration.

The results are consistent with the hypothesis that carnosine is a neurotransmitter or neuromodulator in the olfactory neurons. The results also suggest that carnosine may play a similar role in the vomeronasal neurons.
\end{abstract}

Previous biochemical studies have provided several lines of evidence which suggest that the dipeptide Lcarnosine ( $\beta$-alanyl-L-histidine) may be a neurotransmitter or neuromodulator in the primary olfactory neurons. Carnosine is present in the olfactory epithelium and

\footnotetext{
1 This work was supported by National Instilute of Neurulogical and Communicative Disorders and Stroke Research Grant NS12344 and by the Roche Institute of Molecular Biology. A preliminary account of this work was presented at the Tenth Annual Meeting of the Society for Neuroscience, November 1980. We thank Peter Margolis for technical assistance.

${ }^{2}$ Present address: Department of Neurology, Massachusetts General Hospital, Boston, MA 02114.

${ }^{3}$ To whom reprint requests should be addressed at the Worcester Foundation for Experimental Biology, 222 Maple Avenue, Shrewsbury, MA 01545.
}

olfactory bulb at a concentration 10 to 50 times that of any other brain region (Margolis et al., 1975; Ferriero and Margolis, 1975). Enzymes necessary for the synthesis (carnosine synthetase) and degradation (carnosinase) of carnosine are present and highly active in the olfactory epithelium and olfactory bulb (Harding and Margolis, 1976; Margolis et al., 1975, 1979). Carnosine binding to membranes prepared from mouse olfactory bulbs is saturable, reversible, and stereospecific, and occurs at physiologically significant concentrations (Hirsch et al., 1978; Hirsch and Margolis, 1979). Release of carnosine from olfactory bulb synaptosomes is stimulated by depolariz. ing potassium concentrations and is calcium dependent (Rochel and Margolis, 1982).

Studies on carnosine biochemistry have been aided by the fact that one of the precursor amino acids, $\beta$-alanine, 
is incorporated specifically into carnosine and not into larger peptides and proteins (Margolis and Grillo, 1977). In the present study, we have used intranasal administration of $\beta-\left[{ }^{3} \mathrm{H}\right]$ alanine and autoradiography to demonstrate the localization and transport of carnosine in the primary afferents of the olfactory system in the hamster. Biochemical studies also were carried out to identify the radioactively labeled compounds in the olfactory epithelium and bulb. Autoradiographic results obtained with intranasal $\beta-\left[{ }^{3} \mathrm{H}\right\rceil$ alanine administration were compared to those following $\alpha-\left[{ }^{3} \mathrm{H}\right]$ alanine administration.

\section{Materials and Methods}

Forty-four adult, male hamsters (Mesocricetus auratus) received intranasal administration of radioactive tracers. On the day of administration, the animals were anesthetized with 0.14 to $0.20 \mathrm{ml}$ of Nembutal $(60 \mathrm{mg} /$ ml, i.p.). Twenty minutes after the injection of Nembutal, the hamsters received a $0.20-\mathrm{ml}$ injection of epinephrine bitartrate $(1 \mathrm{mg} / \mathrm{ml}$, i.p. $)$ in physiological saline. The epinephrine used in the biochemical experiments also contained $1 \mathrm{~mm}$ ascorbic acid. Epinephrine has been shown by Meredith and O'Connell (1979) to activate a pumping mechanism that draws fluids into the vomeronasal organ. Twenty-nine of the hamsters were placed on their backs and given a unilateral, intranasal administration of purified $\left.\beta-l^{3} \mathrm{H}\right]$ alanine (83 to $90 \mu \mathrm{Ci}$ in $50 \mu \mathrm{l}$ of deionized water or physiological saline) by inserting the needle of a $100-\mu$ l Hamilton syringe just inside of the right nostril. Each animal remained in this position for 1 to 2 min after the injection and then was returned to its home cage. The other 12 hamsters were treated identically with $\alpha-\left[{ }^{3} \mathrm{H}\right]$ alanine $(83 \mu \mathrm{Ci}$ in $50 \mu \mathrm{l}$ of deionized water).

Autoradiography. Fourteen of the hamsters which received $\beta-\left[{ }^{3} \mathrm{H}\right]$ alanine were sacrificed $6 \mathrm{hr}(N=3), 24 \mathrm{hr}$ $(N=4), 4$ days $(N=4)$, or 18 days $(N=3)$ after the intranasal administrations and were used for autoradiography. The 12 hamsters which were treated intranasally with $\alpha-\left[{ }^{3} \mathrm{H}\right]$ alanine were divided equally into the same four survival groups and also were used for autoradiography. The animals were anesthetized with Nembutal and perfused transcardially with $0.9 \%$ saline followed by a $1 \%$ paraformaldehyde and $1 \%$ glutaraldehyde, $0.1 \mathrm{M}$ phosphate buffer ( $\mathrm{pH}$ 7.4) solution for $30 \mathrm{~min}$. The brains and nasal cavities were removed and placed in additional fixative for 2 days. The brains were dehydrated, cleared with toluene, and embedded in paraffin. The nasal cavities were decalcified for 3 days in $25 \%$ formic acid with $7.5 \%$ sodium citrate, neutralized in $5 \%$ sodium sulfate for 1 day, washed, dehydrated, cleared, and embedded in paraffin. The brains and nasal cavities were cut into 10$\mu \mathrm{m}$-thick coronal sections. These blocks were difficult to section because the glutaraldehyde fixation that was necessary to bind carnosine within the tissue also caused the blocks to become brittle. As a result, some distortion of the tissue sections was encountered. After sectioning, the tissue was mounted onto slides and air-dried. The slides were deparaffinized in xylene and then hydrated. Some of these slides were retained for biochemical analyses (see below) and the remaining slides were processed for autoradiography as described previously (Davis et al.,
1978). In the $\beta-\left[{ }^{3} \mathrm{H}\right]$ alanine groups, the optimal exposure period for our autoradiographs was 16 days at $-17^{\circ} \mathrm{C}$. Shorter periods did not produce sufficient visibility of the autoradiographic grains; longer exposure periods resulted in flaring of the grains, overexposure of the emulsion, and obscuring of the differences in labeling across the survival periods. In order to reduce the variabilities attributable to the processing of the tissue on different occasions, the slides of the olfactory bulbs and nasal cavities from all $\beta-\left[{ }^{3} \mathrm{H}\right]$ alanine-treated animals were dipped and developed at the same time. The optimal exposure period for the $\alpha-\left[{ }^{3} \mathrm{H}\right]$ alanine material was 120 days.

Biochemistry. The intensity of labeling with $\beta-\left[{ }^{3} \mathrm{H}\right]$ alanine in the autoradiographic cases was quantified biochemically. Glass slides with deparaffinized sections of olfactory bulb or nasal cavity adjacent to those taken for autoradiography were scraped to eliminate the tissue from the left side of $\beta-\left[{ }^{3} \mathrm{H}\right]$ alanine-treated animals. The slides then were cut so that portions of the slides containing sections from the right side could be treated individually. Two sections from each animal were placed into separate scintillation vials, moistened with $50 \mu$ l of $\mathrm{H}_{2} \mathrm{O}$, and then covered with $700 \mu \mathrm{l}$ of NCS digestant (Amersham, Inc.). After 16 to $20 \mathrm{hr}$ at room temperature, $13 \mathrm{ml}$ of toluene scintillation solution were added and radioactivity was determined. Preliminary experiments indicated that this treatment gave total solubilization of radioactivity. Counting efficiency was $40 \%$, based on recounting in the presence of an internal standard. Similarly, a second set of sections was placed in $2 \mathrm{ml}$ of $5 \mathrm{M}$ $\mathrm{HCl}$ and held at $85^{\circ} \mathrm{C}$ for $24 \mathrm{hr}$. Although these conditions hydrolyze more than $95 \%$ of carnosine in solution, they were required in order to release radioactivity fully from the tissue sections. The solutions were taken to dryness in a current of air and redissolved in $2 \mathrm{ml} \mathrm{of} 70 \%$ ethanol, and radioactivity was determined on an aliquot. Counting efficiency was $21 \%$, based on recounting in the presence of an internal standard. The balance was analyzed by passage over a Dowex-50 column as indicated below for extracts of fresh tissue.

The incorporation of $\beta-\left[{ }^{3} \mathrm{H}\right]$ alanine into carnosine also was characterized on unfixed tissue. Fifteen of the hamsters which received intranasal administration of $\beta$ $\left[{ }^{3} \mathrm{H}\right]$ alanine in physiological saline were sacrificed by $\mathrm{CO}_{2}$ asphyxiation followed by exsanguination at $6 \mathrm{hr}, 24 \mathrm{hr}$, or 4 days after treatment. Right and left nasal epithelia, right and left olfactory bulbs, and the remaining brain tissue rostral to the cerebellum were dissected individually onto dry ice. The tissues were weighed and then homogenized in $2 \mathrm{ml}$ (bulb or epithelia) or $4 \mathrm{ml}$ (brain) of $70 \%$ ethanol using a Brinkmann Polytron. The homogenates were centrifuged at $27,000 \times g$ for $15 \mathrm{~min}$. Both the supernatant fractions and the pellets were saved for analysis.

Aliquots of the supernatants were applied to $0.5 \times 2.0$ cm Dowex-50 columns prepared in the $\alpha$-picoline form as previously described (Harding and Margolis, 1976; Margolis and Grillo, 1977). The columns were washed sequentially with $4 \mathrm{ml}$ of $\mathrm{H}_{2} \mathrm{O}$, twice with $4 \mathrm{ml}$ of $0.1 \mathrm{M} \alpha$ picoline (prepared from $\alpha$-picoline double distilled over

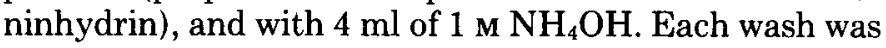


collected separately and counted in a scintillation spectrometer with $10 \mathrm{ml}$ of Hydrofluor (National Diagnostics, Somerville, NJ). The first $4 \mathrm{ml}$ of $\alpha$-picoline contained the $\beta$-alanine, and the $1 \mathrm{M} \mathrm{NH}_{4} \mathrm{OH}$ elutes the carnosine and is referred to as the "carnosine fraction." The radioactivity in the macromolecular fraction was determined by rehomogenizing the pellets resulting from the ethanol precipitation in $2 \mathrm{ml}$ of $10 \%$ trichloroacetic acid and recentrifuging. The final pellets were dissolved in $1 \mathrm{ml}$ ( $3 \mathrm{ml}$ for brain) of concentrated formic acid. One-milliliter aliquots were transferred to scintillation vials with two 1-ml portions of $\mathrm{H}_{2} \mathrm{O}$, mixed with $10 \mathrm{ml}$ of Hydrofluor, and counted in a scintillation spectrometer. The effectiveness of the unilateral irrigation technique was indicated by the observation that the irrigated right side exhibited about 10 times more radioactivity than the unirrigated left side, and therefore, biochemical data will be presented only for tissue from the right olfactory bulb and mucosa.

Counting efficiency was determined with $\left[{ }^{3} \mathrm{H}\right]$ toluene as the internal standard and all values were corrected to disintegrations per min. Efficiencies ranged from 17 to $23 \%$ for the various column eluates and measured $12 \%$ for the formic acid-solubilized pellets.

The $\beta-\left[3-{ }^{3} \mathrm{H}(\mathrm{N})\right]$ alanine $(38.1 \mathrm{Ci} / \mathrm{mmol})$ was prepurified before use on a 2 -cm $\alpha$-picoline Dowex column. The 0.1 м $\alpha$-picoline wash which contained the $\beta$-alanine was taken to dryness in a current of air and redissolved in a small volume of $0.01 \mathrm{M} \mathrm{HCl}$. The $\alpha$-picoline was purified by double distillation over ninhydrin. The $\alpha-\left[3{ }^{3} \mathrm{H}\right]$ alanine $(82.7 \mathrm{Ci} / \mathrm{mmol})$ was used as received. Radiochemicals were purchased from New England Nuclear Corp.; all other chemicals were reagent grade from commercial suppliers.

\section{Results}

Morphology of the nasal cavity and olfactory bulb. The nasal cavity is a bilateral structure divided by the nasal septum. Numerous turbinates extend into the nasal cavity from the lateral walls (Fig. $1 b$ ). In the hamster, the two sides of the nasal cavity are connected caudally via a ventral opening in the septum, the septal window. At the level of the septal window, olfactory epithelium lines all but the most ventral portions of the nasal cavity. The structure and cell types of the mammalian olfactory epithelium have been described previously (Baradi and Bourne, 1953; Moulton and Beidler, 1967; Frisch, 1967; Adams, 1972). The lamina propria lies beneath the olfactory epithelium and contains cells of Bowman's glands, blood vessels, and bundles of olfactory axons surrounded by Schwann cells (cf., Fig. 2c). The vomeronasal organ is located bilaterally at the base of the septum in the rostral third of the nasal cavity (Fig. 1a). This organ contains the chemosensory epithelium (cf., Fig. $4 a$ ) of the accessory olfactory system and its anterior portion opens into the anterior part of the nasal cavity.

The axons of the sensory receptor neurons in the olfactory and vomeronasal epithelia pass through the cribriform bone and terminate in the olfactory bulb. Olfactory receptor neurons project to the main olfactory bulb (MOB), and vomeronasal receptor neurons project to the accessory olfactory bulb (AOB). The MOB is a laminated structure consisting of six layers (olfactory nerve layer, glomerular layer, external plexiform layer, mitral body layer, internal plexiform layer, and granule cell layer) and an ependymal zone (Fig. 1c). Axons of the olfactory receptor neurons run along the surface of the olfactory bulb to form the olfactory nerve layer and
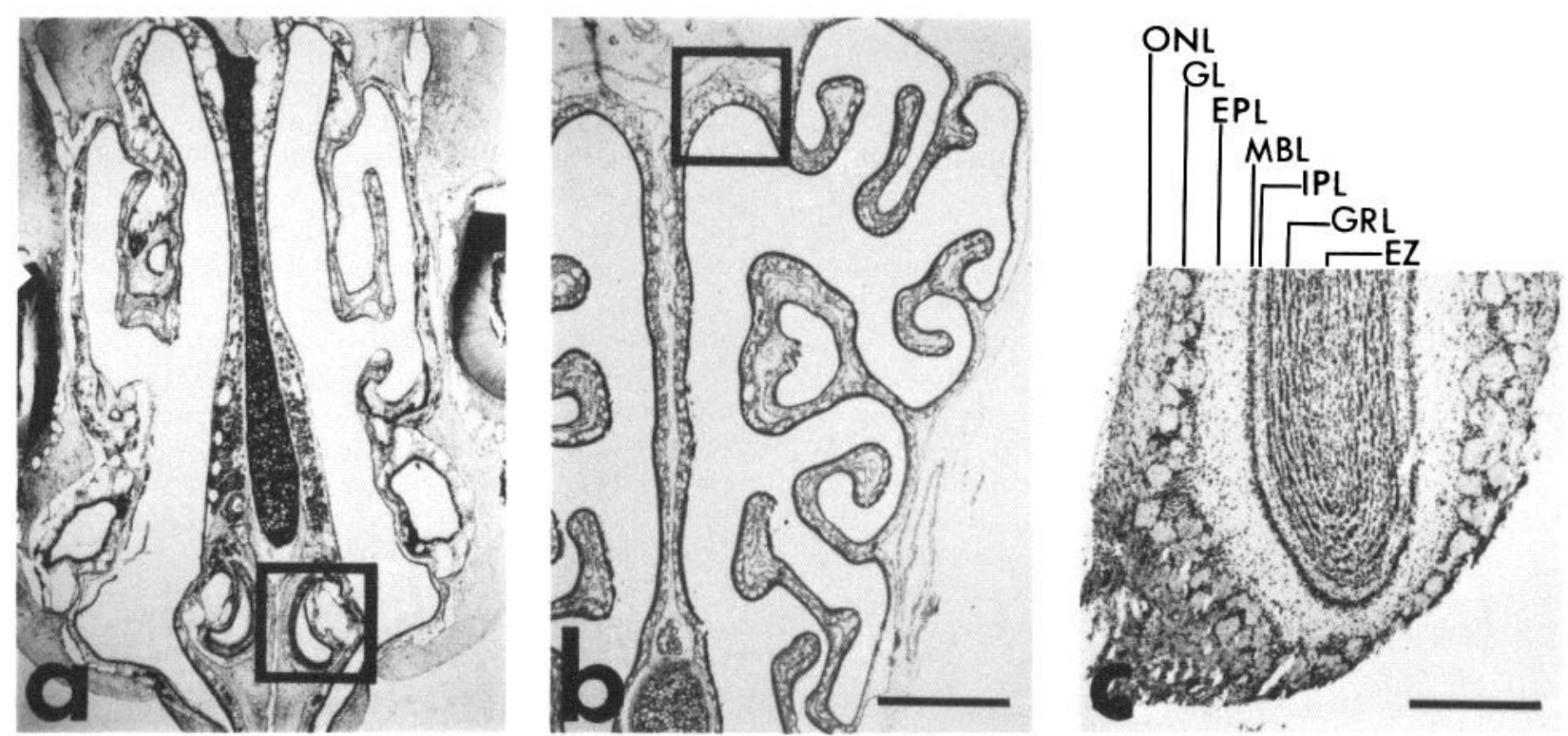

Figure 1. Coronal sections through the rostral nasal cavity $(a)$, caudal nasal cavity $(b)$, and main olfactory bulb $(c)$. $a$, Vomeronasal organ is outlined. Photographs of the vomeronasal organ appear at higher magnification in Figure 4. $b$, Olfactory epithelium lines most of the surface at this level of the nasal cavity. Outlined is the portion of the olfactory epithelium illustrated at higher magnification in Figures 2 and 5. $c$, The laminae of the main olfactory bulb are olfactory nerve layer $(O N L)$, glomerular layer $(G L)$, external plexiform layer $(E P L)$, mitral body layer $(M B L)$, internal plexiform layer $(I P L)$, and granule cell layer $(G R L)$, and there is a distinct ependymal zone (EZ). Calibration bars: $1 \mathrm{~mm}$ for $a$ and $b$; $0.5 \mathrm{~mm}$ for $c$. 
terminate within the glomeruli of the glomerular layer. Bundles of axons of the vomeronasal receptor neurons project along the medial wall of the olfactory bulb and terminate within glomeruli of the AOB. The AOB is a laminated structure consisting of five layers (vomeronasal nerve layer, glomerular layer, external plexiformmitral body layer, internal plexiform layer, and granule cell layer) and is located dorsally in the posterior portion of the main olfactory bulb (cf., Fig. $4 d$ ).

Autoradiography: $\beta$-Alanine. After intranasal administration of $\beta-\left[{ }^{3} \mathrm{H}\right]$ alanine, autoradiographic labeling was present over the tissues of the nasal cavity and the olfactory bulb (Fig. 2). At the earliest survival time examined $(6 \mathrm{hr})$, intranasal irrigation resulted in a nearly uniform labeling of the lissues of the nasal cavity on the side of administration. Some labeling of the tissues along the ventral and medial portions of the contralateral nasal cavity also was observed, probably due to the flow of fluid through the septal window. The labeling of the contralateral side was incomplete and varied across animals. Therefore, the results that follow relate only to the side of administration.

Following intranasal administration of $\beta-\left[{ }^{3} \mathrm{H}\right]$ alanine, the most intense labeling of the tissues of the nasal cavity was observed in the 6-hr survival group (Fig. 2a). Olfactory and respiratory epithelia were labeled and the labeling extended into the lamina propria. While labeling of the entire nasal cavity was quite diffuse at this survival time, there appeared to be more silver grains associated with bundles of olfactory axons within the lamina propria than with other structures.

The intensity of label present in the nasal cavity appeared to decrease over the three remaining survival times. Twenty-four hours after intranasal $\beta-\left[{ }^{3} \mathrm{H}\right]$ alanine irrigation, bundles of axons within the lamina propria were labeled intensely, whereas other structures in the lamina propria, olfactory epithelium, and respiratory epithelium were labeled less intensely (Fig. $2 b$ ). By 4 days after $\beta-\left[{ }^{3} \mathrm{H}\right]$ alanine administration, labeling of the bundles of axons was reduced but was still apparent against the only very light labeling of other structures in the nasal cavity. No label was observed in the nasal cavity after 18 days.

Radioactive label was present in the MOB $6 \mathrm{hr}$ after $\beta-\left[{ }^{3} \mathrm{H}\right]$ alanine administration. Both the olfactory nerve layer and intraglomerular regions of the glomerular layer were labeled intensely (Fig. 2d). The labeling of the MOB was even more intense after $24 \mathrm{hr}$ (Fig. $2 e$ ). Some labeling was present in the deeper layers of the bulb and a thin band of silver grains appeared to be associated with the ependymal cells in the center of the olfactory bulb and with blood vessels (Fig. 3). Much less label was present in the MOB by 4 days (Fig. $2 f$ ) and no label was observed 18 days after $\beta-\left[{ }^{3} \mathrm{H}\right]$ alanine administration.

Intranasal irrigation with $\beta-\left[{ }^{3} \mathrm{H}\right]$ alanine also labeled the accessory olfactory structures. In all cases, the intensity of label present at any given survival time was less in the accessory olfactory structures than in the main olfactory structures. The $\beta-\left[{ }^{3} \mathrm{H}\right]$ alanine entered the vomeronasal organ and labeled the sensory and nonsensory epithelium in the 6-hr survival group (Fig. 4b). Much less label was present in the vomeronasal organ after $24 \mathrm{hr}$ survival (Fig. 4c), and after 4 days, the sensory epithelium was labeled only lightly. After 18 days, the vomeronasal organ was unlabeled.

The time course of labeling in the AOB was similar to that of the MOB. The vomeronasal nerve layer and the glomeruli of the AOB were labeled only lightly at $6 \mathrm{hr}$ after intranasal $\beta-\left[{ }^{3} \mathrm{H}\right]$ alanine irrigation (Fig. $4 e$ ) and showed increased labeling at $24 \mathrm{hr}$ (Fig. 4f). As in the MOB, there appeared to be many more silver grains associated with nonprimary afferent structures $24 \mathrm{hr}$ after the $\beta-\left[{ }^{3} \mathrm{H}\right]$ alanine administration. This labeling, as well as some of the labeling of the primary afferents, was reduced after 4 days. No label was observed in the AOB after 18 days.

Autoradiography: $\alpha$-Alanine. To demonstrate the pattern of labeling in the olfactory bulb and nasal cavity for the four survival times, slides from the $\alpha-\left[{ }^{3} \mathrm{H}\right]$ alanine group had to be exposed for 120 days, which was much longer than the 16-day exposure for $\beta-\left[{ }^{3} \mathrm{H}\right]$ alanine slides. While the results that follow relate only to slides exposed for this period of time, it should be noted that slides of the nasal cavity from the 6 -hr survival group were labeled very intensely with only 14 to 16 days exposure. With this short exposure, these slides demonstrated an intensity and pattern of labeling similar to that observed in the nasal cavity slides from the $6-\mathrm{hr}$ survival, $\beta-\left[{ }^{3} \mathrm{H}\right]$ alanine group.

The intensity of labeling over tissues of the nasal cavity in the $\alpha-\left[{ }^{3} \mathrm{H}\right]$ alanine cases decreased over the four survival times, but these changes were less dramatic than those observed following $\beta-\left[{ }^{3} \mathrm{H}\right]$ alanine administration (Fig. 5). In contrast to the $\beta-\left[{ }^{3} \mathrm{H}\right]$ alanine cases, the $\alpha$ $\left[{ }^{3} \mathrm{H}\right]$ alanine cases did not show a markedly increased specificity of label over bundles of olfactory axons at the 24-hr and 4-day survival times. With increasing survival times, silver grains remained more evenly distributed over the olfactory and respiratory epithelia and the lamina propria. Light labeling of these areas was still apparent after 18 days.

Labeled substances were transported to the olfactory bulb after intranasal $\alpha-\left[{ }^{3} \mathrm{H}\right]$ alanine irrigation, but the rate of transport appeared to be slower than that observed in $\beta-\left[{ }^{3} \mathrm{H}\right]$ alanine-treated hamsters. Light labeling of the olfactory nerve layer and the glomeruli of the MOB was present at $6 \mathrm{hr}$ (Fig. 5c). At $24 \mathrm{hr}$, the olfactory nerve layer was labeled intensely, but the glomeruli were still labeled only lightly. By 4 days, the label was distributed evenly across the olfactory nerve layer and the glomeruli (Fig. $5 d$ ). The most intense labeling of the MOB after $\alpha-\left[{ }^{3} \mathrm{H}\right]$ alanine administration was observed in hamsters following a 4-day survival period. The olfactory nerve layer and the glomeruli of the MOB were still lightly to moderately labeled after 18 days. Labeling of nonprimary afferent structures was not observed at any survival time in the olfactory bulb of $\alpha-\left[{ }^{3} \mathrm{H}\right]$ alaninetreated hamsters.

The label present in the vomeronasal organ and in the AOB after $\alpha-\left[{ }^{3} \mathrm{H}\right]$ alanine administration was much less intense than that observed for the main olfactory system. Label intensity in the vomeronasal organ decreased over 

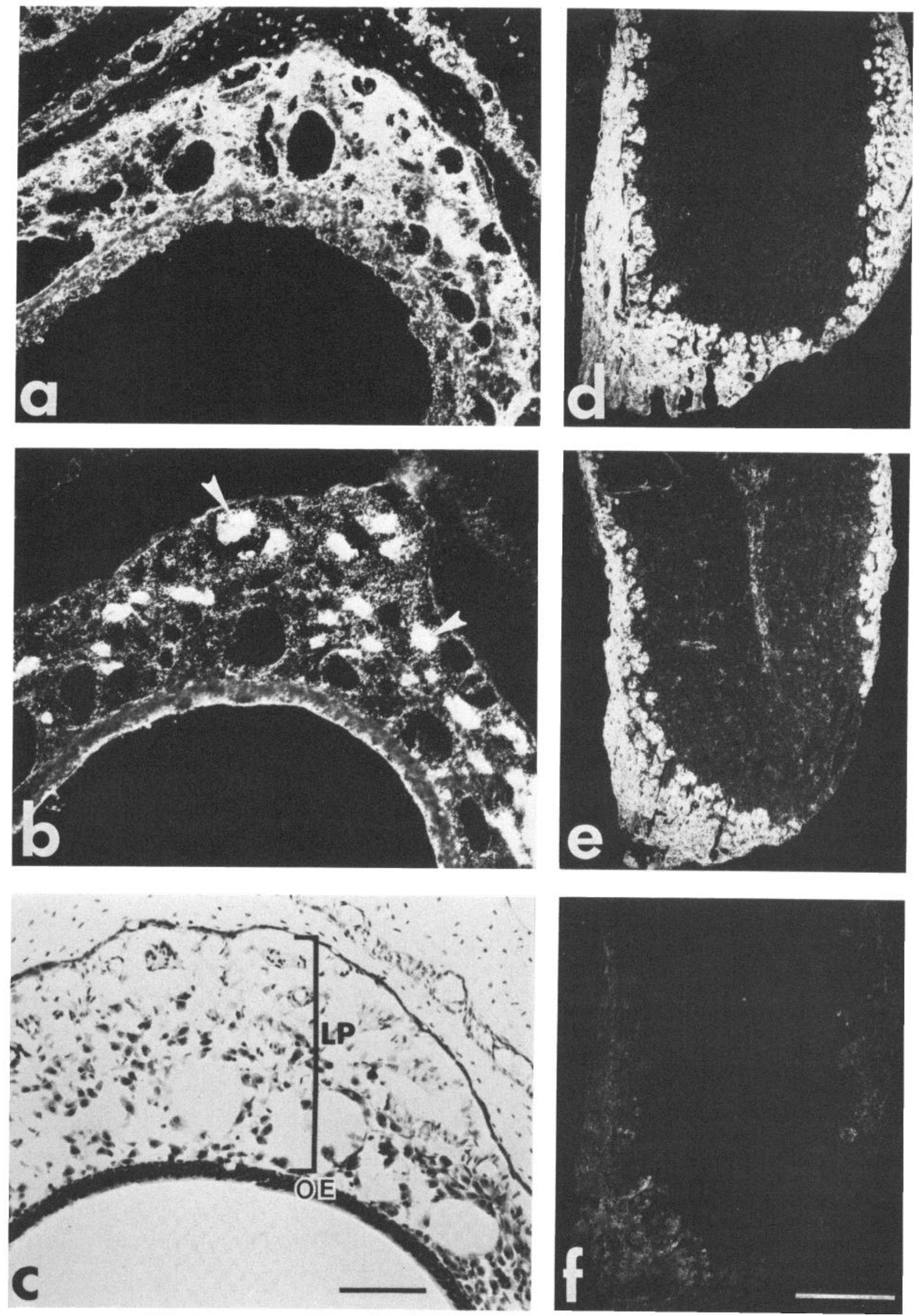

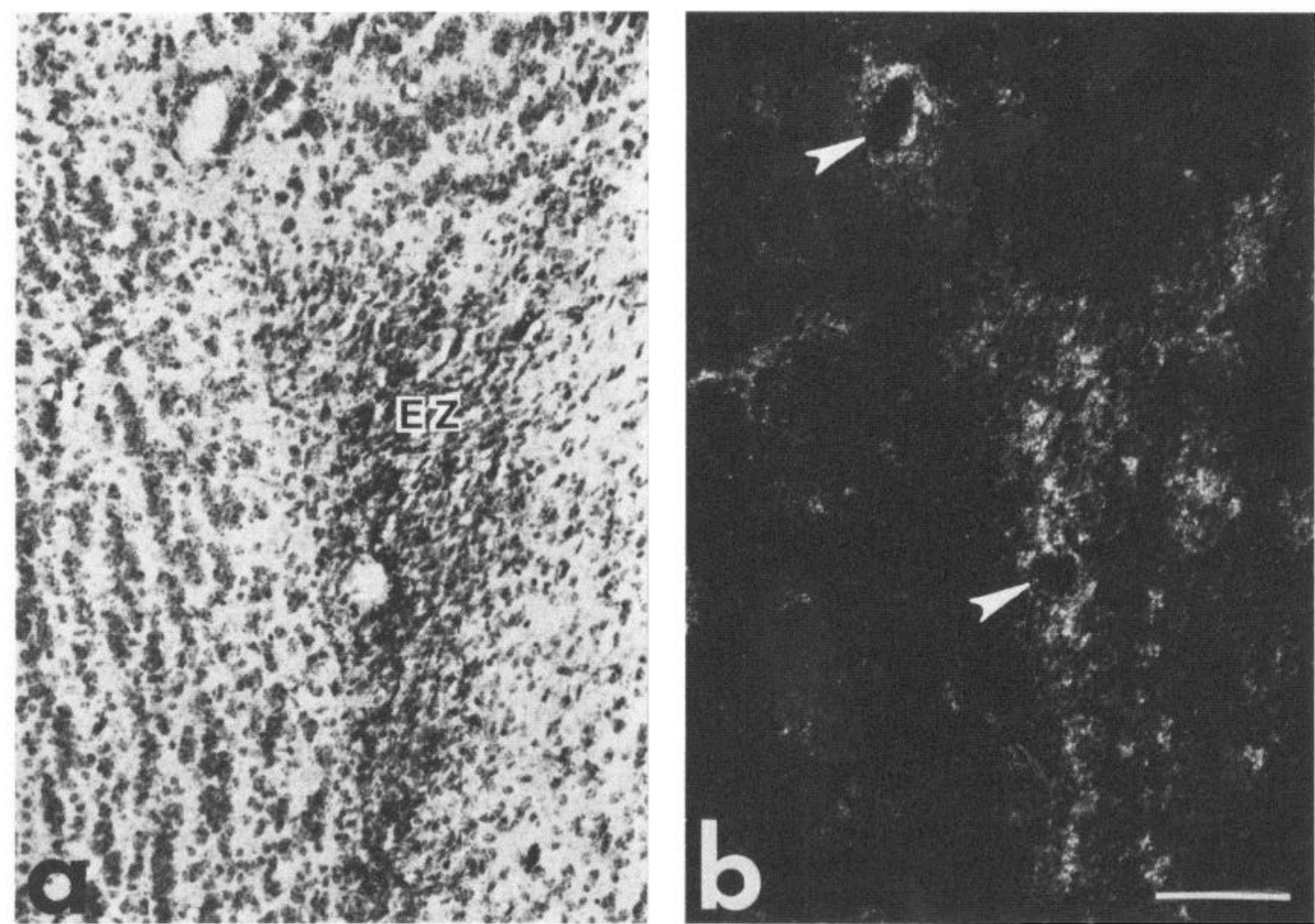

Figure 3. Matching bright-field $(a)$ and dark-field $(b)$ photomicrographs of the deep laminae of the main olfactory bulb $24 \mathrm{hr}$ after intranasal $\beta-\left[{ }^{3} \mathrm{H}\right]$ alanine administration. Silver grains are present over cells around blood vessels (arrowheads) and cells in the ependymal zone (EZ). Calibration bar: $0.1 \mathrm{~mm}$.

the four survival times. This decrease was similar to that observed after $\beta-\left[{ }^{3} \mathrm{H}\right]$ alanine administration. However, unlike the $\beta-\left[{ }^{3} \mathrm{H}\right]$ alanine material, the labeling in the vomeronasal nerve layer and the glomeruli of the $\mathrm{AOB}$ was never intense. Light labeling of the $\mathrm{AOB}$ was observed at all four survival times.

Biochemistry. For comparison with the morphological study and to identify chemically the source of the radioactivity after various survival times, biochemical analyses were performed on unfixed tissue from the olfactory epithelium and bulb and on sections of these tissues fixed and attached to histological slides.

From the biochemical analyses of the radioactivity in the olfactory structures, it was apparent that nearly all of the radioactive label in the olfactory bulb was present as carnosine (Fig. 6; Table I). In the olfactory bulb at all survival times and in the olfactory epithelium at $24 \mathrm{hr}$ and 4 days, at least $82 \%$ of the radioactivity appeared in the carnosine fraction. At the earliest survival time $(6$ $\mathrm{hr}), 61 \%$ of the radioactivity in the olfactory epithelium was present in the carnosine fraction, while $37 \%$ of the label could be accounted for in the $\beta$-alanine fraction. In brain regions caudal to the olfactory bulb and rostral to the cerebellum, the levels of $\left[{ }^{3} \mathrm{H}\right]$ carnosine were very low (Table I), consistent with the low levels of this dipeptide and its synthesizing enzyme in the CNS (cf., Margolis, 1980 , for review) and the presumed difficulty of access of $\beta-\left[{ }^{3} \mathrm{H}\right]$ alanine to these brain regions. The bulk of the radioactivity in extracts of this brain tissue was in the water wash (unbound fraction) from the Dowex column (Table I), was volatile as though it was $\left[{ }^{3} \mathrm{H}_{2} \mathrm{O}\right]$, and was clearly not carnosine. These data are consistent with our prior studies in mice (Margolis and Grillo, 1977).

We have demonstrated that most of the radioactivity in the olfactory tissue is associated with carnosine following intranasal irrigation with $\beta-\left[{ }^{3} \mathrm{H}\right]$ alanine. Interpretation of our autoradiographic data is dependent upon the chemical nature of the radioactivity actually fixed to the tissue. Therefore, it was important to evaluate the quantity of radioactivity actually fixed to the tissue sections and, if possible, to characterize it chemically on slides adjacent to those used for the autoradiographic studies. Fixed histological tissue sections from hamsters sacrificed at various times after intranasal irrigation with $\beta$ $\left[{ }^{3} \mathrm{H}\right]$ alanine were digested by two procedures to evaluate the amount of radioactivity in the section and the prop-

Figure 2. Dark-field photomicrographs of the dorsal fossa of the nasal cavity ( $a$ and $b$ ) and the main olfactory bulb $(d, e$, and $f$ ) after intranasal $\beta-\left[{ }^{3} \mathrm{H}\right]$ alanine administration. The bright-field photomicrograph $(c)$ illustrates the olfactory epithelium $(O E)$ and lamina propria $(L P)$ in thionin-stained material. The dark-field photomicrographs show labeling over structures of the main olfactory system at $6 \mathrm{hr}(a$ and $d), 24 \mathrm{hr}(b$ and $e)$, and 4 days $(f)$. In the nasal cavity at $6 \mathrm{hr}(a)$, the label is present over many structures, but by $24 \mathrm{hr}(b)$, most of the label is associated with bundles of olfactory axons (arrowheads) in the lamina propria. The olfactory nerve and glomerular layers are labeled intensely at $6 \mathrm{hr}(d)$ and $24 \mathrm{hr}(e)$. At $24 \mathrm{hr}$, label is also present in the deep laminae of the olfactory bulb ( $e$; cf., Fig. 3). By 4 days $(f)$, the label in the main olfactory bulb is greatly reduced. Calibration bars: $0.1 \mathrm{~mm}$ for $a, b$, and $c ; 0.5 \mathrm{~mm}$ for $d, e$, and $f$. 

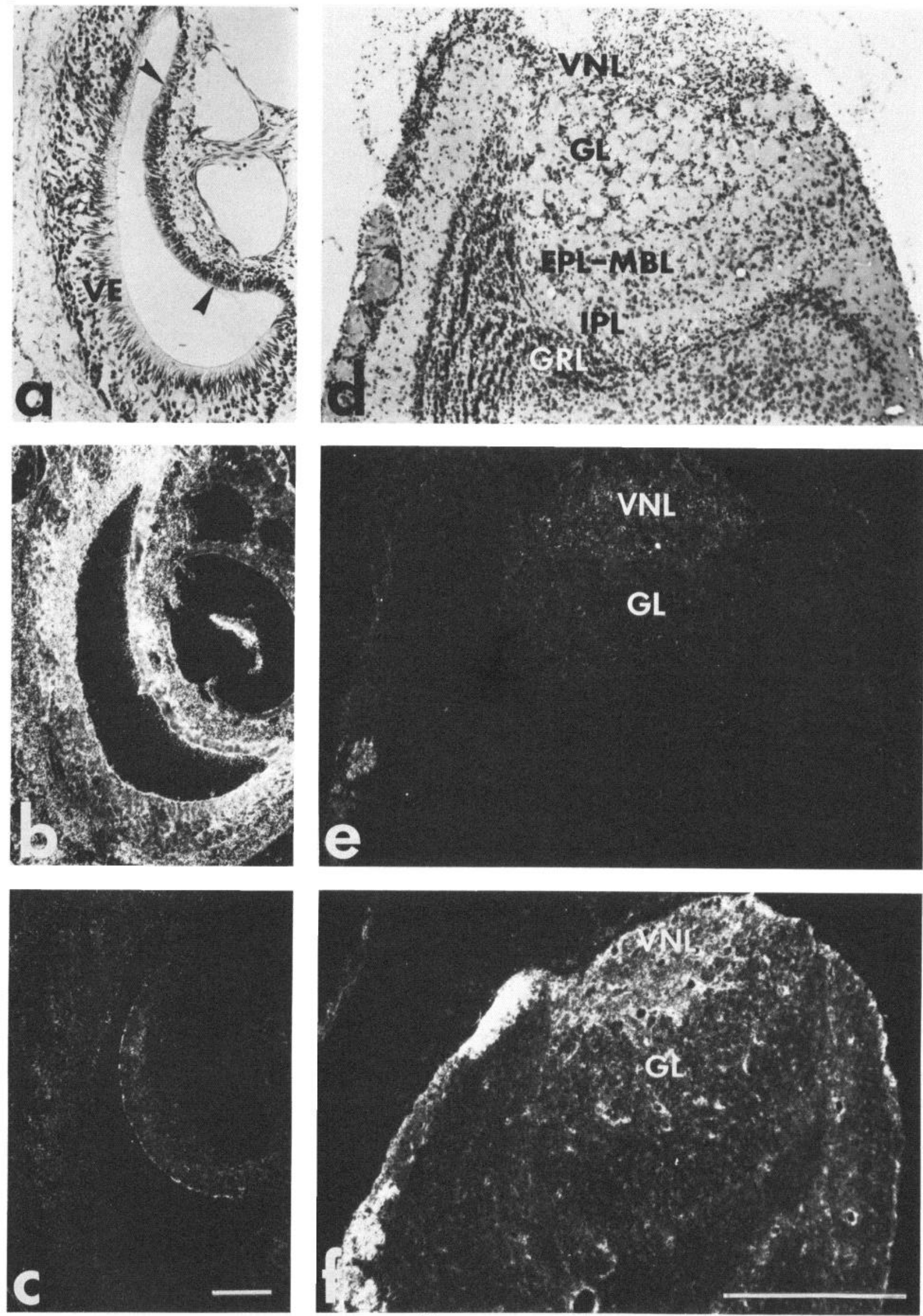

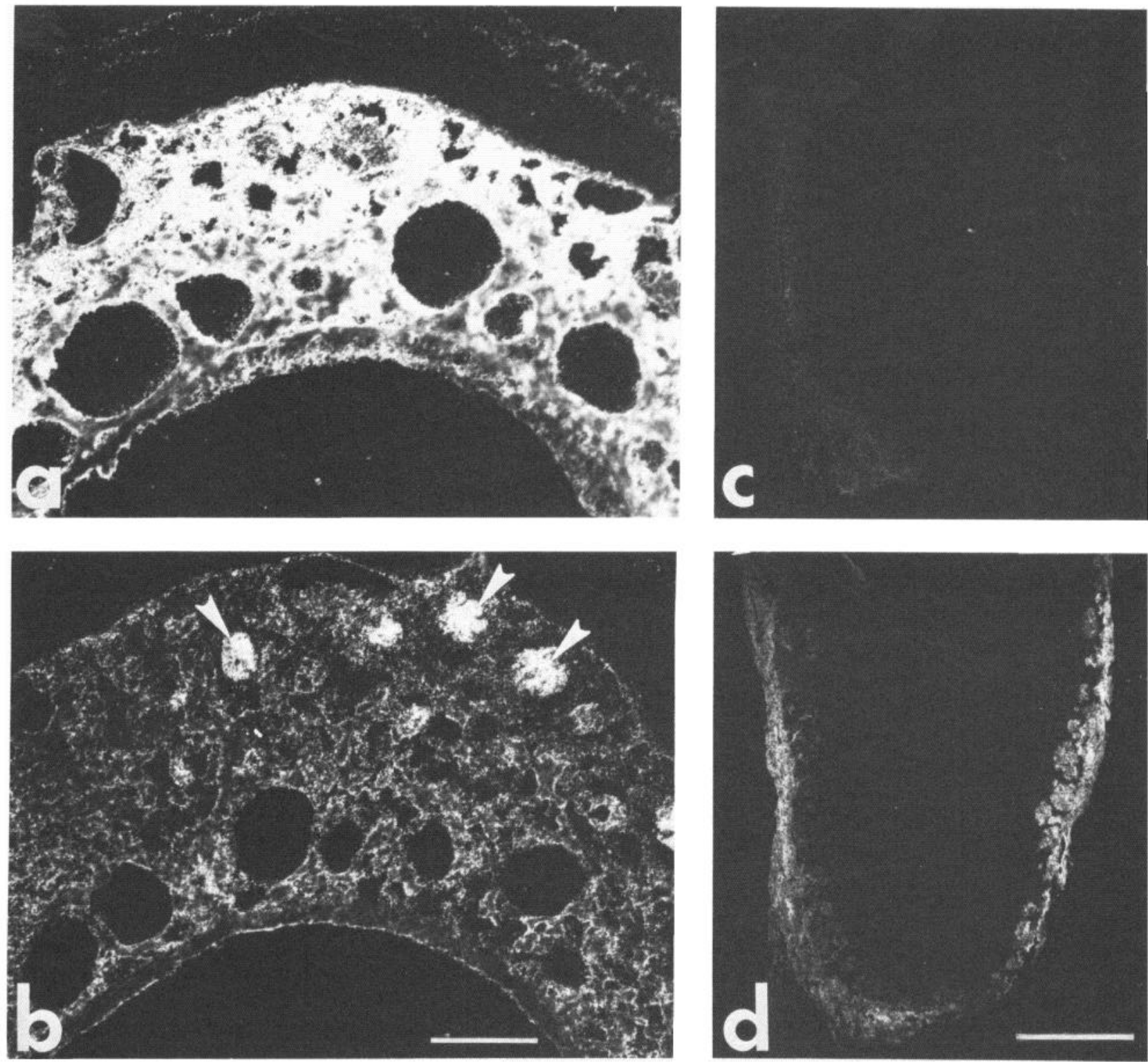

Figure 5. Dark-field photomicrographs of the main olfactory system after $\alpha-\left[{ }^{3} \mathrm{H}\right]$ alanine administration. The lamina propria and olfactory epithelium are labeled intensely at $6 \mathrm{hr}(a)$. Bundles of olfactory axons (arrowheads) and other structures within the nasal cavity remain labeled at 4 days $(b)$. Very little label has reached the main olfactory bulb by $6 \mathrm{hr}(c)$. The most intense labeling in the olfactory bulb was observed at 4 days $(d)$. Calibration bars: $0.1 \mathrm{~mm}$ for $a$ and $b$; $0.5 \mathrm{~mm}$ for $c$ and $d$.

erties of the molecules containing the radioactivity. It was apparent that NCS or $\mathrm{HCl}$ digestion could release similar amounts of radioactivity, indicating that these procedures were equivalent for this purpose (Fig. 7). The radioactivity released exhibited a half-life similar to that seen for chemically identified carnosine (Figs. 6 and 7).

Attempts to release $\left[{ }^{3} \mathrm{H}\right]$ carnosine from the aldehyde- fixed material were unsuccessful, since the conditions required to release ${ }^{3} \mathrm{H}$ from the fixed tissue sections were more stringent than those needed for carnosine hydrolysis. This was perhaps not surprising in view of the complex nature of peptide-aldehyde adducts (French and Edsall, 1945; Olcott and Fraenkel-Conrat, 1947; Monnier and Cerami, 1981). However, we were able to demon-

Figure 4. Photomicrographs of the accessory olfactory system. Bright-field photomicrographs illustrate the vomeronasal organ $(a)$ and the accessory olfactory bulb $(d)$. a, Vomeronasal epithelium $(V E)$ lines the medial and ventral portions, and respiratory epithelium (arrowheads) lines the lateral wall of the vomeronasal organ. $d$, The accessory olfactory bulb contains the following layers: vomeronasal nerve layer $(V N L)$, glomerular layer $(G L)$, external plexiform layer-mitral body layer $(E P L-M B L)$, internal plexiform layer (IPL), and granule cell layer $(G R L)$. Dark-field photomicrographs illustrate labeling in the vomeronasal system $6 \mathrm{hr}(b$ and $e)$ and $24 \mathrm{hr}(c$ and $f)$ after intranasal $\beta-\left[{ }^{3} \mathrm{H}\right]$ alanine administration. At $6 \mathrm{hr}$, the sensory and respiratory epithelia are labeled $(b)$, but little label is present over the accessory olfactory bulb $(e)$. After $24 \mathrm{hr}$, little label remains in the vomeronasal organ (c). The $V N L$ and $G L$ of the accessory olfactory bulb are labeled more intensely at $24 \mathrm{hr}(f)$ than at $6 \mathrm{hr}$ after the $\beta$ - $\left.{ }^{3} \mathrm{H}\right]$ alanine administration. Calibration bars: $0.1 \mathrm{~mm}$ for $a, b$, and $c ; 0.5 \mathrm{~mm}$ for $d, e$, and $f$. 


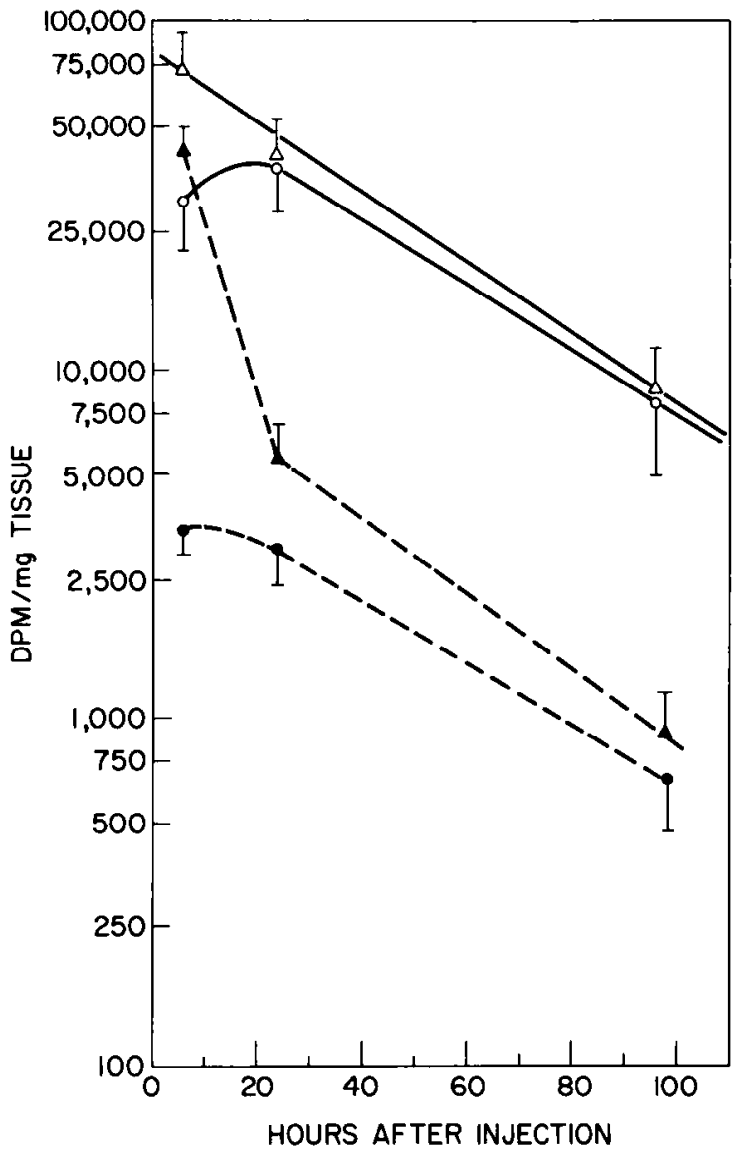

Figure 6. Tine course of $\beta-\left[{ }^{3} \mathrm{H}\right]$ alanine conversion to carnosine following unilateral intranasal administration of $90 \mu \mathrm{Ci}$ / hamster. Data are presented as mean disintegrations per min per mg of tissue $\pm \mathrm{SD}(N=5)$ for carnosine in the olfactory bulb $(O)$ and mucosa $(\triangle)$ and for $\beta$-alanine in the olfactory bulb (O) and mucosa $(\Delta)$. The tissue pellet represented less than $2 \%$ of the total tissue radioactivity. In the brain between the olfactory bulbs and cerebellum, carnosine represents $24 \pm 12$, $107 \pm 57$, and $41 \pm 15 \mathrm{dpm} / \mathrm{mg}$ of tissue $\pm \mathrm{SD}$ at $6 \mathrm{hr}, 24 \mathrm{hr}$, and 4 days, respectively. The half-life of carnosine in the bulb was $32 \mathrm{hr}$ and that in the mucosa was $30 \mathrm{hr}$.

strate that 50 to $60 \%$ of the ${ }^{3} \mathrm{H}$ released on $\mathrm{IICl}$ digestion behaved as $\beta$-alanine on our Dowex- 50 columns, indicating an origin from either $\beta$-alanine or carnosine (data not shown). Although $\beta-\left[{ }^{3} \mathrm{H}\right]$ alanine represented a small fraction of the total tissue radioactivity (Table I), it was conceivable that the differential fixation properties of carnosine and $\beta$-alanine could be such that $\beta$-alanine was fixed preferentially and would, therefore, make a disproportionate contribution to the autoradiography. However, a hamster olfactory bulb is about $3 \mathrm{~mm}$ in length and weighs approximately $20 \mathrm{mg}$. If sections are cut at 10 $\mu \mathrm{m}$ thickness, then 15 sections will represent $1 \mathrm{mg}$ of olfactory bulb. At $24 \mathrm{hr}$, the digested tissue sections contained about 3,000 dpm/section (Fig. 7). Thus, 15 sections represent $45 \times 10^{3} \mathrm{dpm} / \mathrm{mg}$ of tissue. The mean bulb content at $24 \mathrm{hr}$ was $40 \times 10^{3} \mathrm{dpm} / \mathrm{mg}$ of tissue (Fig. 6). This agreement indicates that virtually all of the radioactivity that was transported to the olfactory bulbs was fixed after aldehyde perfusion and that the label visualized in the autoradiographic material therefore predominantly represented $\left[{ }^{3} \mathrm{H}\right]$ carnosine.
TABI.F I

Distribution of counts in Dowex column eluates of ethanol extracts of tissues from hamsters receiving $\beta-\left[{ }^{3} H\right]$ alanine intranasally at various times prior to death

Values represent means of 5 animals at each time point and are expressed as a percentage of the total counts.

\begin{tabular}{lccc}
\hline & $\begin{array}{c}\text { Unbound } \\
\text { Fraction }\end{array}$ & $\begin{array}{c}\beta \text {-Alanine } \\
\text { Fraction }\end{array}$ & $\begin{array}{c}\text { Carnosine } \\
\text { Fraction }\end{array}$ \\
\hline Right bulb & & & \\
$\quad 6 \mathrm{hr}$ & 3 & 10 & 87 \\
$24 \mathrm{hr}$ & 2 & 8 & 90 \\
4 days & 7 & 7 & 84 \\
& & & \\
Right mucosa & 2 & 37 & 61 \\
$6 \mathrm{hr}$ & 2 & 12 & 86 \\
$24 \mathrm{hr}$ & 8 & 9 & 82 \\
4 days & & & \\
& & 10 & 5 \\
Brain & & 3 & 16 \\
$6 \mathrm{hr}$ & 85 & 2 & 9 \\
$24 \mathrm{hr}$ & 81 & & \\
4 days & 89 & & \\
\hline
\end{tabular}

${ }^{a}$ The counts in the unbound fractions of the brain extracts were completely volatile, indicating that these counts represented tritiated water.

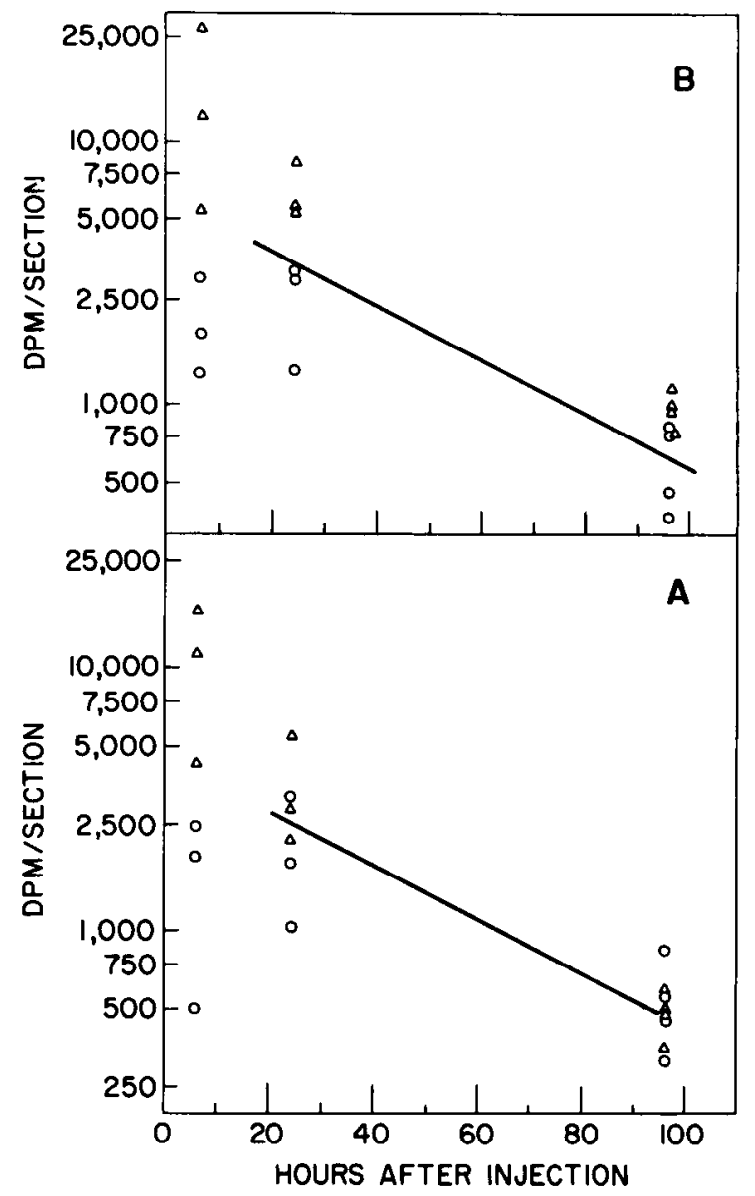

Figure 7. Radioactivity in tissue sections from the nasal cavity $(\triangle)$ and olfactory bulb $(O)$ adjacent to those taken for autoradiography. Data are presented as disintegrations per min per histological section. Each point represents the average of duplicate samples from a given animal. For comparisons, the line represents a calculated decay curve with a half-life of 30 hr. $A$, Radioactivity released after digestion with NCS; $B$, radioactivity released after digestion with $5 \mathrm{M} \mathrm{HCl}$. 


\section{Discussion}

Our autoradiographic findings and biochemical analyses together demonstrate that carnosine is present within the peripheral olfactory axons and is transported in these axons to the olfactory nerve layer and glomeruli of the main olfactory bulb. By comparing these results to the autoradiographic data for the accessory olfactory system, we have provided evidence that carnosine also may be present in the vomeronasal receptor neurons and transported via their axons to the vomeronasal nerve layer and glomeruli of the accessory olfactory bulb.

The pattern of labeling and the time course of transport and metabolism of the labeled compounds after intranasal $\beta-\left[{ }^{3} \mathrm{H}\right]$ alanine administration were similar in both the main and the accessory olfactory systems. In hamsters, the time course of transport of labeled carnosine to the olfactory bulb after intranasal $\beta-\left[{ }^{3} \mathrm{H}\right]$ alanine administration was comparable to that previously reported after $\beta-\left[{ }^{14} \mathrm{C}\right]$ alanine administration to mice (Margolis and Grillo, 1977). While the pattern of labeling in both the main and accessory olfactory systems was similar, the overall intensity of label observed in the accessory olfactory system was less than that observed in the main olfactory system. There may have been less label in the vomeronasal epithelium than in the olfactory epithelium due to differences in access of the $\beta-\left[{ }^{3} \mathrm{H}\right]$ alanine to these tissues; it may have been difficult for fluids to enter the opening of the vomeronasal organ. Alternatively, less carnosine may be present in the accessory olfactory structures. We were unable to determine the chemical nature of labeled compounds in the accessory olfactory system and, thus, do not know if the label was present in $\beta$-alanine, carnosine, or some other compound.

The differences in the pattern and intensity of labeling of the sensory epithelium and olfactory bulb and the different time courses of overall transport from the periphery to the olfactory bulb following intranasal administration of $\alpha-\left[{ }^{3} \mathrm{H}\right]$ alanine and $\beta-\left[{ }^{3} \mathrm{H}\right]$ alanine are consistent with the hypothesis that these two amino acids subserve separate functions in the primary afferent fibers of the chemosensory systems. The olfactory nerve was one of the first systems to be employed for demonstrating anterograde axonal transport using labeled $\alpha$-amino-acids (e.g., Weiss and Holland, 1965; Gross and Beidler, 1973; Land and Shepherd, 1974). Unlike $\beta$-alanine, which is used specifically for the synthesis of carnosine (Margolis and Grillo, 1977), $\alpha$-amino-acids are incorporated into macromolecules and participate in cellular metabolism. After intranasal $\alpha-\left[{ }^{3} \mathrm{H}\right]$ alanine administration in the present study, cells of the sensory and nonsensory epithelium and the lamina propria were labeled. Labeled materials also were transported in the primary afferent fibers to their terminals in the olfactory bulb. 'The amount of $\alpha$ $\left[{ }^{3} \mathrm{H}\right]$ alanine available for axonal transport appeared to be reduced by the distribution of label to many cell types in the nasal cavity and to nontransported cellular components within the somata of receptor cells. This factor and the entrance of $\alpha$-alanine into various metabolic pathways presumably contributed to the lower intensity of label in the nerve layer and glomeruli of $\alpha-\left[{ }^{3} \mathrm{H}\right]$ alaninetreated animals compared with that observed in $\beta$ - $\left[{ }^{3} \mathrm{H}\right]$ alanine-treated animals. With $\alpha-\left[{ }^{3} \mathrm{H}\right]$ alanine administration, the most intense labeling of the olfactory bulb was observed in the 4-day survival group; in $\beta-\left[{ }^{3} \mathrm{H}\right]$ alanine-treated hamsters, peak labeling of the olfactory bulb was observed in the 24-hr survival group. While the rate of transport was not measured, these findings suggest a slower overall rate of transport for $\alpha-\left[{ }^{3} \mathrm{H}\right]$ alanine-labeled molecules than for carnosine labeled with $\beta-\left[{ }^{3} \mathrm{H}\right]$ alanine. If we assume that the $\alpha-\left[{ }^{3} \mathrm{H}\right]$ alanine-labeled molecules predominantly are proteins, this apparent difference in the rate of transport is consistent with the common finding in other neural systems that the amount of protein carried in slow axonal transport is much larger than that in fast transport, whereas neuropeptides and other putative neurotransmitter molecules primarily are carried by fast transport (for review, see Grafstein and Forman, 1980). It is also possible that the $\alpha$-alaninelabeled molecules have slower clearance rates than carnosine and that the different times of peak labeling in the olfactory bulb reflect differences in the balance of accumulation and clearance for these compounds.

As mentioned above, the most intense labeling of the main and accessory olfactory bulbs was observed $24 \mathrm{hr}$ after intranasal $\beta-\left[{ }^{3} \mathrm{H}\right]$ alanine administration. At this survival time, not only were the axons and terminals of the chemosensory fibers intensely labeled, but many silver grains appeared to be associated with nonprimary afferent structures. Previous reports have shown that anterograde axonal transport of labeled materials may be followed by release of radioactivity from the terminals (see review of Grafstein and Forman, 1980). In turn, there is evidence that release may be followed by some form of transneuronal transport (Grafstein, 1971; Graftstein and Laureno, 1973; Specht and Grafstein, 1973) or uptake by glial cells (Hamberger, 1971; Henn and Hamberger, 1971; Bauman et al., 1974; Hösli et al., 1972) or pericytes and endothelial cells of brain capillaries (Hamberger and Masuoka, 1965; Hamberger, 1967). After intranasal $\beta$ $\left[{ }^{3} \mathrm{H}\right]$ alanine administration, labeled compounds did not appear to be transported to second order neurons in the olfactory bulb. Specifically, the somata of the mitral, tufted, and periglomerular cells were not labeled. Distant projection sites of mitral and tufted cells were not examined specifically in this study and, thus, rapid transneuronal transport of carnosine or a metabolite without accumulation of labeled material in the soma cannot be ruled out. Such transport is unlikely, however, because we did not observe autoradiographic labeling in the lateral olfactory tract. Rather, the nonprimary afferent labeling observed $24 \mathrm{hr}$ after $\beta$-[31] alanine irrigation appeared to be associated with non-neuronal cells. Many silver grains were present over the ependymal cells in the center of the granule cell layer of the main olfactory bulb, were associated with blood vessels, and were, to a lesser extent, distributed throughout the neuropil of the olfactory bulb. This finding suggests that, $24 \mathrm{hr}$ after intranasal $\beta-\left[{ }^{3} \mathrm{H}\right]$ alanine administration, ependymal cells, perivascular cells, and glial cells in the olfactory bulb may contain a labeled compound released from the primary afferent fibers.

Nonprimary afferent labeling after intranasal administration of tritiated amino acids also was observed by Barber and Raisman (1974). They found label in layers 
deep to the glomerular layer of the main and accessory olfactory bulbs after peripheral afferent labeling with $\left[{ }^{3} \mathrm{H}\right]$ proline. As in our study with $\beta-\left[{ }^{3} \mathrm{H}\right]$ alanine, they observed that the most intense labeling of nonprimary afferent structures occurred in cases where the glomeruli were labeled heavily. They reported that the silver grains were not concentrated over nuclei of neurons or glial cells. A similar pattern of nonprimary afferent labeling was observed occasionally in the olfactory bulbs of mice treated intranasally with a mixture of $\left[{ }^{3} \mathrm{H}\right]$ leucine and $\left[{ }^{3} \mathrm{H}\right]$ proline and sacrificed after 6 to $8 \mathrm{hr}$ (Burd, 1979). This was observed only in cases where the glomeruli were labeled intensely. Thus, the visibility of nonprimary afferent labeling observed after transport of labeled materials from the periphery to the olfactory bulb may be dependent upon the quantity of label present in the primary afferents or upon the amino acid used in the study. After intranasal $\alpha-\left[{ }^{3} \mathrm{H}\right]$ alanine administration, nonprimary afferent labeling was not observed at any survival time. However, the intensity of glomerular labeling never reached that of the $\beta-\left[{ }^{3} \mathrm{H}\right]$ alanine-treated cases with $24-\mathrm{hr}$ survivals. It is also possible that $\alpha$ $\left[{ }^{3} \mathrm{H}\right]$ alanine is released from the primary afferents but, for unknown reasons, is not fixed to nonprimary afferent structures by our perfusion procedures.

In the $\beta-\left[{ }^{3} \mathrm{H}\right]$ alanine-treated cases, although the nature of the labeled compound in nonprimary afferent structures could not be distinguished from the labeled material in primary afferent fibers, it was quantitatively much less. Biochemical analyses of homogenates of whole bulb tissue demonstrated that 84 to $90 \%$ of the total radioactivity in the olfactory bulb at all survival times was present in the carnosine fraction, while an additional 7 to $10 \%$ was present in the $\beta$-alanine fraction. This finding indicates that most of the labeled material in nonprimary afferent structures is either carnosine or $\beta$-alanine. This labeled material is not likely to be carnosine for the following reasons. Although depolarization-dependent release of carnosine can be demonstrated from synaptosomal fractions (Rochel and Margolis, 1982), carnosine uptake cannot be so demonstrated (A. Keller, S. Rochel and F. L. Margolis, unpublished observations). In addition, carnosinase activity in the bulb is partially membrane associated (F. L. Margolis and M. Grillo, unpublished observations) and is present in nonprimary afferent structures (Margolis, 1975, Harding and Margolis, 1976). Furthermore, $\beta$-alanine uptake by glial cells has been demonstrated in several tissues (Lodge et al., 1976; Schon and Kelly, 1975), including olfactory bulb (Priestley et al., 1979). Thus, it is probable that radioactive carnosine is released from the olfactory axon terminals, diffuses through the extracellular space, and is hydrolyzed by carnosinase, and the radioactive $\beta$-alanine so produced is taken up by glial and other non-neuronal cells, giving rise to the radioactivity seen in nonprimary afferent structures.

In summary, this study provides the first direct demonstration that the dipeptide carnosine is localized and transported to the olfactory bulb in the axons of primary olfactory neurons. This demonstration, based on combined anatomical and biochemical techniques, is fully consistent with previous biochemical studies utilizing various acute, chronic, and reversible neural lesion techniques (for review, see Margolis, 1980). The results of these studies together with those on carnosine binding (Hirsch et al., 1978; Hirsch and Margolis, 1979) and release (Rochel and Margolis, 1982) support the hypothesis that carnosine may be a neurotransmitter or neuromodulator in the primary olfactory neurons.

\section{References}

Adams, D. R. (1972) Olfactory and non-olfactory epithelia in the nasal cavity of the mouse, Peromyscus. Am. J. Anat. 133: 37-50.

Baradi, A. F., and G. H. Bourne (1953) Gustatory and olfactory epithelia. Int. Rev. Cytol. 2: 289-330.

Barber, P. C., and G. Raisman (1974) An autoradiographic investigation of the projection of the vomeronasal organ to the accessory olfactory bulb in the mouse. Brain Res. 81: 21-30.

Bauman, A., S. Bourgoin, P. Benda, J. Glowinski, and M. Hamon (1974) Characteristics of tryptophan accumulation by glial cells. Brain Res. 66: 253-263.

Burd, G. D. (1979) A light and electron microscopic study on the mouse olfactory bulb and epithelium after intranasal zinc sulfate irrigation. Doctoral dissertation, University of North Carolina, Chapel Hill.

Davis, B. J., F. Macrides, W. M. Youngs, S. P. Schneider, and D. L. Rosene (1978) Efferents and centrifugal afferents of the main and accessory olfactory bulbs in the hamster. Brain Res. Bull. 3: 59-72.

Ferriero, D., and F. L. Margolis (1975) Denervation in the primary olfactory pathway of mice. II. Effects on carnosine and other amine compounds. Brain Res. 94: 75-86.

French, D., and J. T. Edsall (1945) The reactions of formaldehyde with amino acids and proteins. Adv. Protein Chem. 3: 277-335.

Frisch, D. (1967) Ultrastructure of mouse olfactory mucosa. Am. J. Anat. 121: 87-120.

Grafstein, B. (1971) Transneuronal transfer of radioactivity in the central nervous system. Science 172: 177-179.

Grafstein, B., and D. S. Forman (1980) Intracellular transport in neurons. Physiol. Rev. 60: 1168-1283.

Grafstein, B., and R. Laureno (1973) Transport of radioactivity from eye to visual cortex in the mouse. Exp. Neurol. 39: 44-57.

Gross, G. W., and L. M. Beidler (1973) Fast axonal transport in the C-fibers of garfish olfactory nerve. J. Neurobiol. 4: 413-428.

Hamberger, A. (1971) Amino acid uptake in neuronal and glial cell fractions from rabbit cerebral cortex. Brain Res. 31: $169-178$.

Hamberger, B. (1967) Reserpine-resistant uptake of catecholamines in isolated tissues of the rat. A histochemical study. Acta Physiol. Scand. Suppl. 295: 4-63.

Hamberger, B., and D. Masuoka (1965) Localization of catecholamine uptake in rat brain slices. Acta Pharmacol. Toxicol. (Copenh.) 22: 363-368.

Harding, J., and F. L. Margolis (1975) Denervation in the primary olfactory pathway of mice. III. Effect on enzymes of carnosine metabolism. Brain Res. 110: 351-360.

Henn, F. A., and A. Hamberger (1971) Glial cell function: Uptake of transmitter substances. Proc. Natl. Acad. Sci. U. S. A. $68: 2686-2690$.

Hirsch, J. D., and F. L. Margolis (1979) L-[3H]Carnosine binding in the olfactory bulb. 11. Biochemical and biological studies. Brain Res. 174: 81-94.

Hirsch, J. D., M. Grillo, and F. L. Margolis (1978) Ligand binding studies in the mouse olfactory bulb: Identification 
and characterization of a $\mathbf{L}-\left[{ }^{3} \mathrm{H}\right]$ carnosine binding site. Brain Res. 158: 407-422.

Hösli, E., A. Ljungdahl, T. Hökfelt, and L. Hösli (1972) Spinal cord tissue cultures-a model for autoradiographic studies on uptake of putative neurotransmitters such as glycine and GABA. Experientia 28: 1342-1344.

Land, L. J., and G. M. Shepherd (1974) Autoradiographic analysis of olfactory receptor projections in the rabbit. Brain Res. 70: 506-510.

Lodge, D., G. A. R. Johnston, and A. L. Stephenson (1976) The uptake of GABA and $\beta$-alanine in slices of cat and rat CNS tissue: Regional differences in susceptibility to inhibitors. J. Neurochem. 27: 1569-1570.

Margolis, F. L. (1975) Biochemical markers of the primury olfactory pathway: A model neural system. In Advances in Neurochemistry, B. Agranoff and M. Aprison, eds., Vol. 1, pp. 193-246, Plenum Press, New York.

Margolis, F. L. (1980) Carnosine: An olfactory neuropeptide. In The Role of Peptides in Neuronal Function, J. L. Barker and T. G. Smith, Jr., eds., pp. 545-572, Marcel Dekker, Inc., New York.

Margolis, F. L., and M. Grillo (1977) Axoplasmic transport of carnosine ( $\beta$-alanyl-L-histidine) in the mouse olfactory pathway. Neurochem. Res. 2: 507-519.

Margolis, F. L., D. Ferriero, and J. Harding (1975) Carnosine ( $\beta$-alanyl-L-histidine) in the olfactory nerve: A putative transmitter candidate. In Proceedings of the Sixth International Congress of Pharmacology, L. Ahtee, ed., Vol. 2, pp. 61-69, Forssan Kirjapaino Oy, Forssan, Finland.
Margolis, F. L., M. Grillo, C. E. Brown, T. H. Williams, R. G. Pitcher, and G. J. Elgar (1979) Enzymatic and immunological evidence for two forms of carnosinase in the mouse. Biochim. Biophys. Acta 570: 311-323.

Meredith, M., and R. J. O'Connell (1979) Efferent control of stimulus access to the hamster vomeronasal organ. J. Physiol. (Lond.) 286: 301-316.

Monnier, V. M., and A. Cerami (1981) Nonenzymatic browning in vivo: Possible process for aging of long-lived proteins. Science 211: 491-493.

Moulton, D. G., and I. M. Beidler (1967) Structure and function in the peripheral olfactory system. Physiol. Rev. 47: 1-52.

Olcott, H. S., and H. Fraenkel-Conrat (1947) Specific group reagents for proteins. Chem. Rev. 41: 151-197.

Priestley, J. V., J. S. Kelly, and A. Claudio Cuello (1979) Uptake of $\left[{ }^{3} \mathrm{H}\right]$ dopamine in periglomerular cells of the rat olfactory bulb: An autoradiographic study. Brain Res. 165: 149-155.

Rochel, S., and F. L. Margolis (1982) Carnosine release from olfactory bulb synaptosomes is calcium dependent and depolarization stimulated. J. Neurochem., in press.

Schon, F., and J. S. Kelly (1975) Selective uptake of $\left[{ }^{3} \mathrm{H}\right] \beta$ alanine by glia: Association with the glial uptake system for GABA. Brain Res. 86: 243-257.

Specht, S., and B. Grafstein (1973) Accumulation of radioactive protein in mouse cerebral cortex after injection of ${ }^{3} \mathrm{H}$-fucose into the eye. Exp. Neurol. 41: 705-722.

Weiss, P. A., and Y. Holland (1965) Neuronal dynamics and axonal flow, II. The olfactory nerve as model test object. Proc. Natl. Acad. Sci. U. S. A. 57: 258-264. 